\title{
The Role and Importance of Antiagregan, Anticoagulant Drugs in the Etiology of Upper Gastrointestinal System Bleeding in Elderly
}

\author{
Hanife Şerife Aktaş
}

Department of Internal Medicine, Health Sciences University, Umraniye Training and Research Hospital, Istanbul, Turkey

\begin{abstract}
Introduction: In this study, we aimed to determine the role of anticoagulants and antiagregan medications in the etiology and prognosis of the upper gastrointestinal system (GIS) bleeding in elderly patients.

Methods: One hundred and eighty-four patients who were admitted to the emergency department with the complaints of upper GIS bleeding between January and December 2016 were evaluated retrospectively regarding the age, gender, complaints, drugs, endoscopy findings, intensive care requirement and mortality.

Results: The mean age of 184 patients was $78.3 \pm 7.9$ years. 112 (60.9\%) of them were male and 72 (39.1\%) of them were female. 128 (69.6\%) of the patients applied with only melena, 32(17.4\%) with only hematemesis and 24 (13\%) were admitted with both hematemesis and melena. Of the patients, 139 (75.9\%) were treated in the internal medicine clinic and 31 (16.8\%) were treated in the intensive care unit and 12 (6.5\%) were expired. The most commonly used drug was acetylsalicylic acid (ASA) (31.5\%) and the most common endoscopic finding was peptic ulcer (55.4\%). The mean age of the patients treated in the intensive care unit was $81 \pm 7.2$ years, and 18 (58.1\%) of those patients were male. The most common endoscopic finding was peptic ulcer- Forrest 2A (16.2\%) and ASA (35.5\%) was also the most common drug in that group. The mean age of the 12 patients who were expired was $75.3 \pm 7.2$ years and 8 (66.7\%) of them were male. In 12 patients, the most common endoscopic finding was the peptic ulcer and the most frequent drug was warfarin (33\%).

Discussion and Conclusion: Antiagregan, anticoagulant, NSAl drugs have significant effects on etiology and prognosis of the upper GIS bleeding in the elderly. Gastroprotective drugs should be added to the treatment of patients using these drugs.

Keywords: Antiagregan drugs; anticoagulant drugs; elderly; GIS bleeding.
\end{abstract}

U pper gastrointestinal bleeding (GIS) is an important cause of mortality and morbidity ${ }^{[1]}$. Its incidence is $103 / 100.000$ per year and constitutes $80-85 \%$ of all GIS bleedings. Although $80 \%$ of bleedings in patients spontaneously stop, $20 \%$ of them are severe. Although there have been many improvements in modern surgical techniques, intensive care treatments, endoscopic diagnosis and treatments in recent years, mortality is still high and it is around $2-10 \%{ }^{[2,3]}$. The incidence and mortality rates of GIS bleeding increase with age.
Especially patients over 60 years of age account for $35-45 \%$ of all the cases with upper gastrointestinal bleedings ${ }^{[4]}$. The incidence of upper GIS bleeding in patients older than 70 years is $20-30$ times higher than 30 -year-old patients. Furthermore, the mortality rate due to GIS bleeding in patients in this age group is $12-25 \%{ }^{[5]}$. Multiple drug use is common in the elderly population due to chronic diseases. Nonsteroidal anti-inflammatory drugs (NSAIDs) are the most important cause of GIS bleeding in this age group. In addition, the use of antiaggregant and/or anticoagulant

Correspondence (Illetişim): Hanife Şerife Aktaş, M.D. Saglik Bilimleri Universitesi, Umraniye Egitim ve Arastirma Hastanesi, Ic Hastaliklari Anabilim Dali, 34773, Istanbul, Turkey

Phone (Telefon): +90 5322810919 E-mail (E-posta): drhsaktas@gmail.com

Submitted Date (Başvuru Tarihi): 04.07.2018 Accepted Date (Kabul Tarihi): 28.08.2018

Copyright 2019 Haydarpaşa Numune Medical Journal

OPEN ACCESS This is an open access article under the CC BY-NC license (http://creativecommons.org/licenses/by-nc/4.0/). 
drugs frequently due to concomitant cardiovascular, cerebrovascular diseases increases the risk of GIS bleeding in these patients ${ }^{[4]}$.

In this study, we aimed to determine the role of anticoagulant and antiaggregant drugs in the etiology and prognosis of upper gastrointestinal bleeding in patients aged 65 years and older.

\section{Materials and Methods}

A total of 184 patients aged 65 years and over who were admitted to the emergency internal medicine department of our hospital between January and December 2016 with complaints of hematemesis and melena and followed up with the diagnosis of upper GIS bleeding were evaluated retrospectively. Patients were evaluated in terms of age, gender, admission complaints, drug use and type (NSAIDs, antiaggregants, anticoagulants), endoscopy findings, need for intensive care, and mortality.

Approval of the Ethics Committee of our hospital was obtained for this study (B.10.1.TKH.4.34.H.GP.0.01/71). Statistical analyzes were performed using MedCalc Statistical Software version 12.7.7 (MedCalc Software bvba, Ostend, Belgium; http://www.medcalc.org; 2013). Descriptive statistics were used to define continuous variables (mean, standard deviation, minimum, median, maximum) Statistical significance level was determined as $p=0.05$.

\section{Results}

A total of 184 patients with upper gastrointestinal bleeding were included in this study. The mean age of the patients was $78.3 \pm 7.9$ years. Of these, $112(60.9 \%)$ were male and 72 were female. When the age and sex distribution of the patients were examined, 66 (58.9\%) of the patients between the ages of $65-75$ were male, and $10 \%(13.9 \%)$ of them were female, while 34 male (30.4\%), and $30(41.7 \%)$ female patients were in the age group of $75-85$ years. However, 12 (10.7\%) of them were male, and 32 (44.4\%) of them were female patients in the age bracket of 85-95 years. Upper Gl bleeding was most frequently seen in the 6-7 decades (Table 1).

The patients were admitted to the hospital with the complaints of only melena $(n=128: 69.6 \%)$, hematemesis $(n=32$ $: 17.4 \%)$, and both with hematemesis and melena $(n=24: 13 \%)$.

The most common findings in upper GIS endoscopy were peptic ulcer $(55.4 \%)$, gastritis $(25 \%)$, esophageal variceal bleeding (7.6\%), and gastric cancer (7.6\%). When the patients with peptic ulcer were examined according to Forrest classification most frequently (63.7\%) Forrest 3 peptic ulcer was observed followed by Forrest $2 B(15.6 \%)$, Forrest $2 \mathrm{~A}(8.8 \%)$, and Forrest $1 \mathrm{~A}(7.8 \%)$ peptic ulcer in decreasing order of frequency (Table 2). When the gender distribution
Table 1. Demographic data

\begin{tabular}{|c|c|c|c|c|c|}
\hline \multirow{4}{*}{ Age (year) } & \multicolumn{2}{|c|}{$\mathbf{n}$} & Mean \pm SD & \multicolumn{2}{|c|}{ Median (Min-Max) } \\
\hline & \multicolumn{2}{|c|}{184} & $78.3+7.9$ & \multicolumn{2}{|c|}{79 (65-95) } \\
\hline & \multicolumn{2}{|c|}{ Male } & \multicolumn{2}{|c|}{ Female } & \multirow{2}{*}{$\begin{array}{c}\text { Total } \\
\mathbf{n}\end{array}$} \\
\hline & $\mathbf{n}$ & $\%$ & $\mathbf{n}$ & $\%$ & \\
\hline $65-75$ & 66 & 58.9 & 10 & 13.9 & 76 \\
\hline $75-85$ & 34 & 30.4 & 30 & 41.7 & 64 \\
\hline \multirow[t]{2}{*}{$85-95$} & 12 & 10.7 & 32 & 44.4 & 44 \\
\hline & $\mathbf{n}$ & $\%$ & & & \\
\hline \multicolumn{6}{|l|}{ Sex } \\
\hline Male & 112 & 60.9 & & & \\
\hline Female & 72 & 39.1 & & & \\
\hline
\end{tabular}

Table 2. Distribution of parameters

\section{n}

\section{$\%$}

Complaints

Hematemesis

17.4

Hematemesis+Melena

Melena

32

24

128

13.0

Endoscopic

Gastritis+Esophagitis

Findings

Gastritis

Gastric Ca

Normal

Esophagitis

Esophageal Ulcer

Esophageal varices

Peptic ulcer

Forrest 1A

Forrest 1B

Forrest 2A

Forrest 2B

Forrest 2C

Forrest 3

69.6

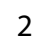

1.1

\section{6}

$$
14
$$

2

2

2

14

102

8

2

2

16

2

65

Number of drugs used

0

1

2

ASA

NSAD

Clopidogrel

Warfarin

Rivaroxaban

Apixaban

Dabigatran

Enoxaparin

Prognosis

Ex

Discharge

Hospitalisation

Intensive care
25.0 
was examined according to the endoscopy findings, it was observed that $51.7 \%$ of men and $61.1 \%$ of women had peptic ulcers (Table 3).

When the patients were evaluated in terms of the drugs they used, 134 (72.8\%) of the patients were using drugs that could cause GIS bleeding, 108 (58.7\%) were one kind of medication, and 26 (14.1\%) patients were taking two drugs at the same time. In order of decreasing frequency the drugs used were acetylsalicylic acid (ASA) (31.5\%), NSAID (20.7\%), clopidogrel (13\%), warfarin (7.6\%), rivaroxaban (6.5\%), apixaban (3.3\%), dabigatran (6\%), and enoxaparin sodium (1.1\%). When the drug distributions were examined according to the endoscopy findings, in users of NSAIDs, ASA or dabigatran most frequently peptic ulcer $(79 \%, 62 \%, 67 \%$, respectively) was seen, while gastritis was most often (57.1\%) observed in warfarin users (Table 4).

Of these 184 patients presenting with complaints of upper GIS bleeding, 139 (75.9\%) were treated in the internal medicine clinic, 31 (16.8\%) in the intensive care unit and two in emergency observation room (Table 2). The mean age of 31 patients who were in need of intensive care was $81 \pm 7.2$ years, while $58 \%$ of them were male, and $42 \%$ of them were female. Most frequently (16.2\%) Forrest $2 \mathrm{~A}$ peptic ulcer was found in endoscopy findings and $35.5 \%$ of these patients were using ASA (Table 5).

The mean age of 12 deceased patients was $75.3 \pm 7.2$ years,

Table 3. Endoscopic findings and their distribution between genders

\begin{tabular}{ccccc}
\multicolumn{2}{c}{ Male } & & \multicolumn{2}{c}{ Female } \\
\cline { 5 - 6 }$(112)$ & & & $n$ & $\%$ \\
& & & $(72)$ &
\end{tabular}

\begin{tabular}{lcccc}
\hline Endoscopic Findings & & & & \\
Gastritis+ Esophagitis & 0 & 0.0 & 2 & 2.8 \\
Gastritis & 28 & 25.0 & 18 & 25.0 \\
Gastric Ca & 10 & 8.9 & 4 & 5.6 \\
Normal & 0 & 0.0 & 2 & 2.8 \\
Esophagitis & 2 & 1.8 & 0 & 0.0 \\
Esophageal Ulcer & 2 & 1.8 & 0 & 0.0 \\
Esophageal Varices & 10 & 8.9 & 4 & 5.6 \\
Peptic Ulcer & 58 & 51.7 & 44 & 61.1 \\
$\quad$ Forrest 1A & 4 & 3.6 & 4 & 5.6 \\
$\quad$ Forrest 1B & 0 & 0.0 & 2 & 2.8 \\
$\quad$ Forrest 2A & 9 & 8.1 & 0 & 0.0 \\
Forrest 2B & 10 & 8.9 & 6 & 8.4 \\
Forrest 2C & 0 & 0.0 & 2 & 2.8 \\
Forrset 3 & 35 & 31.3 & 30 & 38.9 \\
\hline
\end{tabular}

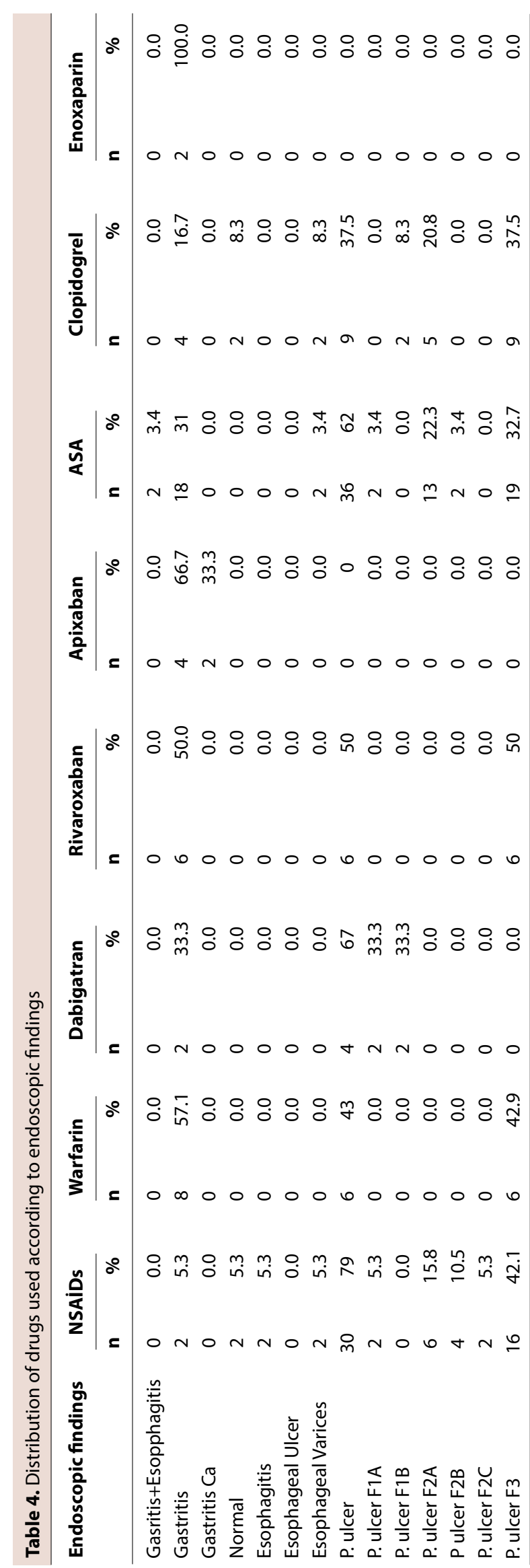


while $66.7 \%$ of them were male and $33.3 \%$ of them were female. Two of these 12 patients had gastric cancer. The other 10 (83\%) patients had GIS bleeding due to peptic ulcer detected during their endoscopic examination. These patients were using warfarin (33\%), rivaroxaban (16\%), or an NSAID (16\%) (Table 6).

\section{Discussion}

In the last century, with the prolongation of human life, an older society started to emerge and digestive system diseases of the elderly population started to be seen more frequently. Despite all the improvements in diagnosis and treatment, acute GIS bleeding still exists as a serious and

Table 5. Characteristic features of the patients who need intensive care

\begin{tabular}{cccc} 
& $\mathbf{n}$ & Mean \pm SD & Median (Min-Max) \\
\hline Age (year) & 31 & $81.4+7.2$ & $82(70-95)$ \\
\hline & & $\mathbf{n}$ & $\%$ \\
\hline
\end{tabular}

\begin{tabular}{|c|c|c|}
\hline \multicolumn{3}{|l|}{ Gender } \\
\hline Male & 18 & 58.1 \\
\hline Female & 13 & 41.9 \\
\hline \multicolumn{3}{|l|}{ Complaints } \\
\hline Hematemesis & 7 & 22.6 \\
\hline Hematemesis+Melena & 8 & 25.8 \\
\hline Melena & 16 & 51.6 \\
\hline \multicolumn{3}{|l|}{ Endoscopic findings } \\
\hline Gasritis+ Esophagitis & 0 & 0.0 \\
\hline Gastritis & 4 & 12.9 \\
\hline Gastric Ca & 4 & 12.9 \\
\hline Normal & 0 & 0.0 \\
\hline Esophagitis & 2 & 6.5 \\
\hline Esophageal Ulcer & 0 & 0.0 \\
\hline Esophageal Vari & 0 & 0.0 \\
\hline Peptic ulser & 19 & 48.5 \\
\hline Forrest $1 \mathrm{~A}$ & 4 & 12.9 \\
\hline Forrest 1B & 2 & 6.5 \\
\hline Forrest $2 \mathrm{~A}$ & 5 & 16.2 \\
\hline Forrest 2B & 0 & 0.0 \\
\hline Forrest $2 \mathrm{C}$ & 0 & 0.0 \\
\hline Forrest 3 & 4 & 12.9 \\
\hline ASA & 11 & 35.5 \\
\hline NSAID & 9 & 29.0 \\
\hline Dabigatran & 6 & 19.4 \\
\hline Apixaban & 2 & 6.5 \\
\hline Clopidogrel & 2 & 6.5 \\
\hline Rivaroxaban & 0 & 0.0 \\
\hline Warfarin & 0 & 0.0 \\
\hline Enoxaparin & 0 & 0.0 \\
\hline
\end{tabular}

fatal clinical problem. Especially, $90 \%$ of deaths caused by acute gastrointestinal bleeding consisted of elderly patients ${ }^{[4]}$.

NSAIDs are widely used for chronic pain in older people. In addition, secondary to the frequent use of antiaggregant and anticoagulant drugs for the treatment of cardiovascular and cerebrovascular diseases, the incidence of GIS bleeding increases. Mortality also increases in this age group due to other accompanying diseases ${ }^{[6]}$. NSAIDs show analgesic, antipyretic and anti-inflammatory effects by inhibiting cyclooxygenase (COX) enzyme. Aspirin is the prototype of this group of drugs which is defined as non-

Table 6. Clinical characteristics, and endoscopic findings of deceased patients

\begin{tabular}{cccc}
\hline & $\mathbf{n}$ & Mean+SD & Median (Min-Max) \\
\hline Age (year) & 12 & $75.3+7.2$ & $74(67-86)$ \\
\hline & & $\mathbf{n}$ & $\%$
\end{tabular}

Gender

$\begin{array}{lll}\text { Male } & 8 & 66.7 \\ \text { Female } & 4 & 33.3\end{array}$

Complaints

Hematemsis $\quad 43.3$

$\begin{array}{lll}\text { Hem+Mel } & 2 & 16.7\end{array}$

$\begin{array}{lll}\text { Melena } & 6 & 50.0\end{array}$

Endoscopic

$\begin{array}{lll}\text { Gastritis+Esophagitis } & 0 & 0.0\end{array}$

Findings

$\begin{array}{lll}\text { Gastritis } & 0 & 0.0\end{array}$

$\begin{array}{lll}\text { Gastric Ca } & 2 & 16.7\end{array}$

Normal $\quad 0 \quad 0.0$

Esophagitis $\quad 0 \quad 0.0$

Esophageal Ulcer $\quad 0 \quad 0.0$

Esophageal Varices $\quad 0 \quad 0.0$

$\begin{array}{lll}\text { Peptic ulcer } & 10 & 83.4\end{array}$

$\begin{array}{lll}\text { Forrest } 1 \mathrm{~A} & 2 & 16.7\end{array}$

Forrest 1B $\quad 0 \quad 0.0$

$\begin{array}{lll}\text { Forrest } 2 \mathrm{~A} & 2 & 16.7\end{array}$

Forrest 2B $\quad 0 \quad 0.0$

Forrest $2 \mathrm{C} \quad 0 \quad 0.0$

Forrest $3 \quad 6 \quad 50$

$\begin{array}{lll}\text { Warfarin } & 4 & 33.3\end{array}$

$\begin{array}{lll}\text { Rivaroxaban } & 2 & 16.7\end{array}$

$\begin{array}{lll}\text { NSAIDs } & 2 & 16.7\end{array}$

$\begin{array}{lll}\text { Apixaban } & 0 & 0.0\end{array}$

Dabigatran $\quad 0 \quad 0.0$

$\begin{array}{lll}\text { ASA } & 0 & 0.0\end{array}$

Clopidogrel $\quad 0 \quad 0.0$

Enoxaparin $\quad 0 \quad 0.0$ 
steroidal anti-inflammatory drugs (NSAIDs). NSAIDs affect the gastrointestinal system mucosa negatively and cause damage. Local and systemic mechanisms in combination play a role in this effect.

With direct effect on stomach and duodenum mucosa, they may lead to epithelial damage and superficial petechia, with resultant occult, and massive bleedings. NSAIDs also inhibit the synthesis of cytoprotective prostaglandins by inhibiting the COX enzyme.

The cytoprotective effects of prostaglandins include increasing bicarbonate release and increasing resistance to superficial epithelium against injury, enhancing mucosal regeneration and mucosal blood flow. NSAIDs inhibit all these mucosal protective mechanisms of prostaglandins and cause GIS bleeding ${ }^{[7-9]}$.

Yalçın et al. reported that $52.6 \%$ of the patients who had GIS bleeding used ASA and NSAID. In the study of Günşar

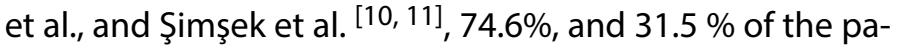
tients with complaints of GIS were using these drugs, respectively. In our study, ASA was used in $31.5 \%$ and NSAID in $20.7 \%$ of the patients. In other words, $52.2 \%$ of our patients were using NSAIDs and/or ASA.

In our study, $60.9 \%$ of the patients were male and $39.1 \%$ of them were female. The male/female ratios differed in various studies (Fleischer et al. ${ }^{[12]} 2.19 / 1$, Paspatis et al. ${ }^{[13]}$ 2.4/1 and Zaltman et al. ${ }^{[14]} 1.7 / 1$. In our study, the male/ female ratio was $1.5 / 1$, which was consistent with the literature. It has been reported in many previous studies that male gender is an independent risk factor for upper $\mathrm{Gl}$ bleeding ${ }^{[15]}$.

The use of endoscopy in upper GIS bleeding is the most appropriate method for both correct diagnosis and interventional treatment ${ }^{[16]}$. In a study published in JAGS in the year 2010 on 113 patients over 65 years of age, the most common cause of upper GIS bleeding was reportedly gastritis and duodenal ulcer $(66 \%){ }^{[17]}$. Yalçın et al. also reported causes of upper gastrointestinal bleeding as a peptic ulcer (63.2\%), erosive gastroduodenitis (16.3\%) and esophageal varices (9.4\%).

Also, in our study, the most common causes of upper GIS bleeding in this age group were peptic ulcer (55.4\%), gastritis (25\%) and esophageal varices (7.6\%). Mortality rates in acute upper gastrointestinal bleeding are still high, despite medical treatment and interventional treatment mortality rates range between 2 and 10\%. When the mortality rates in the literature are examined, in a study conducted by Clason et al., ${ }^{[18]}$ mortality rates of $3 \%$ and $35 \%$ were reported in patients under and over 60 years of age, respectively. In the studies of Aksöz et al., Ercan et al., Ünsal and Şimşek et al. mortality rates of $7.4 \%, 6.2 \%$, and $6 \%$ were repoprted, respectively ${ }^{[19]}$. In our study, the mortality rate was $6.5 \%$ in accordance with the literature. When we examined our twelve deceased patients in our study, we found gastric cancer in two, and upper gastrointestinal bleeding due to peptic ulcer in 10 patients. In addition, these deceased patients were using oral anticoagulants (warfarin and rivaroxaban) more frequently. This condition suggests us that the presence of other concomitant diseases as cerebrovascular diseases, atrial fibrillation, and cardiovascular diseases that require the use of oral anticoagulants contribute considerably to mortality rates, and in some cases, we thought that the patients died not from GIS bleeding but from other concomitant diseases.

Morbidity and mortality rates increase with age in patients with upper gastrointestinal bleeding. The presence of concomitant diseases, the amount, and recurrence of bleeding, the success in achieving endoscopic hemostasis, the characteristic feature of the lesion causing the bleeding are factors that affect the prognosis. When we examined the characteristics of the patients treated in the intensive care units in our study, we found that these patients were relatively older (mean age, 81.4 \pm 7.2 years), and the most common cause of bleeding (16.2\%) was Forrest 2a- peptic ulcer.

\section{Conclusion}

ASA, clopidogrel, NSAIDS and oral anticoagulant drugs play an important role in the etiology of upper gastrointestinal bleeding seen in the elderly. Therefore, these drugs should be used with caution in the elderly patient population, and their indications should be well-reviewed. Addition of gastric protective drugs should not be neglected if necessary for the treatment of patients using ASA and NSAID. Especially very old people with concomitant systemic disease(s) should be treated under intensive-care conditions.

Ethics Committee Approval: Approval of the Ethics Committee of Umraniye Training and Research Hospital was obtained for this study (B.10.1.TKH.4.34.H.GP.0.01/71).

Peer-review: Externally peer-reviewed.

Conflict of Interest: None declared.

Financial Disclosure: The author declared that this study received no financial support.

\section{References}

1. Longstreth GF. Epidemiology of hospitalization for acute upper gastrointestinal hemorrhage: a population based study. Am J Gastroenterol 1995;90:206-10. 
2. Szura M, Pasternak A. Upper non-variceal gastrointestinal bleeding review the effectiviness of endoscopic hemostasis methods. World J Gastrointest Endosc 2015;7:1088-95.

3. Sandel MH, Kolkman JJ, Kuipers EJ, Cuesta MA, Meuwissen SG. Nonvariceal upper gastrointestinal bleeding:differences in outcome for patients admitted to internal medicine and gastroenterological services.Am. J.Gastroenterol 2000;95:235762.

4. Rockall TA,Logan RFA, Devlin HB.Northfield TC.Risk assessment after acute upper gastrointestinal haemorrhage.Gut 1996; 38:316-21.

5. Peter DJ, Dougherty JM. Evaluation of the patient with gastrointestinal bleeding: an evidence based approach. Emerg Med Clin North Am 1999;17:239-61.

6. Palmer K.Acute upper gastrointestinal haemorrhage. $\mathrm{Br}$ Med Bull 2007;83:307-24.

7. Solomon DH. NSAIDs: Overview of adverse effects. UpToDate 2009;17:2.

8. McCarthy D. Nonsteroidal anti-inflammatory drug-related gastrointestinal toxicity: Definition and epidemiology. Am J Med 1998;105:3S-9S.

9. Bombardier $C$, Laine L, Reicin A, Shapiro D, Burgos-Vargas R, Davis $B$, et al; VIGOR Study Group. Comparison of upper gastrointestinal toxicity of rofecoxib and naproxen in patients with rheumatoid arthritis. VIGOR Study Group. N Engl J Med 2000;343:1520-28.

10. Wolfe MM, Lichtenstein DR, Singh G. Gastrointestinal toxicity of nonsteroidal antiinflammatory drugs. N Engl J Med 1999;340:1888-9.

11. Yalçın MS, Kara B, Öztürk NA, Ölmez Ş, Taşdoğan BE, Taş A. Epidemiology and endoscopic findings of the patients suffer- ing from upper gastrointestinal system bleeding. Dicle Med J 2016;43:73-6.

12. Boonpongmance $S$, Fleischer DE, Pezzula JC, Collier K, Mayoral W, Al-Kawas F, et al. The frequency of peptic ulcer as a cause of acute upper Gl bleeding is exaggerated. Gastrointest Endosc 2004; 59:788-94.

13. Paspatis GA, Matrella E, Kapsoritakis A, Leontithis C, Papanikolaou N, Chlouverakis GJ, et al. An epidemiological study of acute upper gastrointestinal bleeding in Crete, Greece. Eur J Gastroenterol hepatol 2000;12:1215-20.

14. Zaltman C, Souza HS, Castro ME, Sobral Mde F, Dias PC, Lemos $\checkmark$ Jr.Upper gastrointestinal bleeding in a Brazilian hospital: a retrospective study of endoscopic records.Arq Gastroenterol 2002;39:74-80.

15. Feldman M, Friedman LS, Sleisenger MH, Gastrointestinal and liver disease : pathophysiology, diagnosis, management. 7th ed. Philadelhia: Saunders; 2002.p. 211-43.

16. Lee JG. What is the value of early endoscopy in upper gastrointestinal bleeding? Nat Clin Pract Gastroenterol Hepatol 2006;3:534-5.

17. Alkhatib AA, Elkhatib FA, Alkhatib AA, Maldonado A, Abubakr SM, Adler DG. Acute upper gastrointestinal bleeding in elderly people: presentations, endoscopic findings and outcomes. J Am Geriatr Soc 2010;58:182-5.

18. Yenigün CE, Pirpir A, Aytan P, Ulusal G, Yıldırım IS. Evaluation of the characteristics of patients with upper gastrointestinal system bleeding. Akademik Gastroenteroloji Dergisi 2006;5:116-22.

19. Şimşek Z, Harzadın T, Yıldırm iS. Üst gastrointestinal sistem kanamalı 161 hastanın değerlendirilmesi. MN-Klinik Bilimler \& Doktor 2003;9:675-80. 